\title{
MODEL EVALUASI KINERJA KARYAWAN DENGAN METODE FUZZY SUGENO PADA RESTO ABTL
}

\author{
Fanisya Alva Mustika ${ }^{1}$, Sutrisno \\ Program Studi Teknik Informatika, Universitas Indraprasta PGRI Jakarta ${ }^{1,2}$ \\ E-mail: alva.mustika@gmail.com ${ }^{1}$ \\ E-mail: sutrisno3831@gmail.com²
}

\begin{abstract}
Abstrak
Kualitas sumber daya manusia merupakan salah satu faktor dalam meningkatkan produktivitas kinerja suatu instansi. Oleh karena itu, diperlukan sumber daya manusia yang mempunyai kompetensi tinggi karena keahlian atau kompetensi akan dapat mendukung peningkatan prestasi kerja karyawan. Penilaian kinerja harus dilakukan untuk mengetahui prestasi yang dicapai setiap karyawan dengan baik, cukup baik atau kurang bisa diketahui. Permasalahan yang terjadi pada Resto ABTL adalah belum adanya format yang baku mengenai evaluasi penilaian karyawan. Untuk mengatasi permasalahan tersebut dibutuhkan sistem pendukung keputusan yang dapat membantu manajer dalam menentukan karyawan dengan kinerja terbaik (Employee of The Month), serta memberikan saran membangun karyawan berdasarkan nilai yang diperoleh. Model evaluasi kinerja karyawan adalah sistem evaluasi yang dirancang untuk mengidentifikasi kinerja karyawan dalam melaksanakan tugasnya. Model tersebut menggunakan logika fuzzy sugeno dengan beberapa kriteria, yaitu: kehadiran, pelayanan, penampilan, kerjasama dan tanggung jawab. Kriteria dibagi dalam himpunan fuzzy Buruk, Cukup, dan Baik. Dari kriteria tersebut dibuat model penilaian kinerja dalam evaluasi kinerja karyawan. Hasil dari penelitian ini adalah model evaluasi kinerja karyawan dapat dibuat model sistem pendukung keputusan dengan pendekatan fuzzy.
\end{abstract}

Kata Kunci :Karyawan, Fuzzy, Sugeno, Employee of The Month.

\section{Pendahuluan}

\section{Latar Belakang}

Kualitas sumber daya manusia merupakan salah satu faktor dalam meningkatkan produktivtas kinerja suatu instansi. Oleh karena itu, diperlukan sumber daya manusia yang mempunyai kompetensi tinggi karena keahlian atau kompetensi akan dapat mendukung peningkatan prestasi kerja karyawan. Penilaian kinerja harus dilakukan untuk mengetahui prestasi yang dicapai setiap karyawan dengan baik, cukup baik atau kurang bisa diketahui.

Kinerja karyawan yang dilakukan di Resto ABTL digunakan mengevaluasi hasil kerja seluruh karyawan dengan menggunakan kriteria komitmen yang dinilai kehadiran, pelayanan, penampilan, kerjasama dan tanggung jawab. Model evaluasi kinerja karyawan adalah sistem evaluasi yang dirancang untuk mengidentifikasi kinerja karyawan dalam melaksanakan tugasnya.

\section{Tujuan Penelitian}

Penelitian ini bertujuan untuk :

a. Merancang model evaluasi kinerja karyawan dengan metode fuzzy sugeno pada resto ABTL. Dengan adanya aplikasi ini diharapkan proses evaluasi kinerja karyawan dapat dengan mudah dilakukan untuk memudahkan pengambilan keputusan manajerial.

b. Melakukan pengujian terhadap aplikasi yang dihasilkan. 


\section{Manfaat Penelitian}

Manfaat yang diharapkan dari aplikasi ini adalah untuk memudahkan manajer dalam melakukan evaluasi kinerja karyawan, selain itu menjadi sumbangan bagi restoran untuk memudahkan dalam pengambilan keputusan manajerial.

Hasil luaran yang diharapkan dari penelitian ini adalah berupa model evaluasi kinerja karyawan sehingga diharapkan manajer resto dapat mengambil keputusan manajerial dengan cepat dan tepat.

\section{Tinjauan Pustaka}

1. Karyawan

Menurut Undang-undang No.13 Tahun 2003 Tentang Ketenagakerjaan Bab I, Pasal 1 ayat 2. Tenaga kerja adalah setiap orang yang mampu melakukan pekerjaan guna menghasilkan barang dan atau jasa baik untuk memenuhi kebutuhan sendiri maupun untuk masyarakat.

2. Penilaian Kinerja

Kinerja adalah hasil seseorang secara keseluruhan selama periode tertentu di dalam melaksanakan tugas, seperti standar hasil kerja, target atau sasaran atau kriteria yang telah ditentukan terlebih dahulu dan telah disepakati bersama. (Rivai dan Basri, 2004).

Penilaian Kinerja adalah suatu sistem formal dan terstruktur yang mengukur, menilai, dan mempengaruhi sifat-sifat yang berkaitan dengan pekerjaan, perilaku, dan hasil, termasuk tingkat ketidakhadiran.fokusnya adalah untuk mengetahui seberapa produktif seorang karyawan dan apakah ia bisa berkinerja sama atau lebih efektif pada masa yang akan datang, sehingga karyawan, organisasi, dan masyarakat semuanya memperoleh manfaat. (Schuler dan Jackson dalam Jurnal SDM)

3. Employee of The Month

Salah satu sistem reward yang digunakan adalah dengan mengadakan pemilihan karyawan terbaik pada bulan tersebut (Employee of the month).Pemberian reward penghargaan merupakan salah satu usaha perusahaan untuk memberikan balas jasa atas pencapaian atau hasil kerja pegawai sehingga pegawai termotivasi untuk melakukan pekerjaan dengan lebih baik lagi.Penghargaan yang diberikan dimaksudkan untuk meningkatkan produktivitas dan mempertahankan karyawan yang berprestasi agar tetap berada dalam perusahaan.Apabila produktivitas pegawai meningkat maka hal ini juga merupakan keuntungan bagi perusahaan. Dengan demikian baik pegawai atau perusahaan akan sama-sama diuntungkan atau bisa dikatakan dengan istilah win-win result.

4. Fuzzy

Sebelum munculnya teori logika fuzzy logic dikenal sebuah logika tegas (crisp logic) yang memiliki nilai benar dan salah secara tegas. Sebaliknya Logika fuzzy adalah suatu logika yang memiliki nilai kekaburan atau kesamaran (fuzzyness) antara benar dan salah. Dalam teori logika fuzzysuatu nilai bisa bernilai benar dan salah secara bersamaan. Namun berapa besar kebenaran dan kesalahan suatu nilai tergantung pada bobot keanggotaan yang dimilikinya. Orang yang belum mengenal logika fuzzy pasti akan mengira bahwa logika fuzzy adalah suatu yang amat rumit dan tidak menyenangkan. Namun, sekali orang mengenalnya, ia pasti akan sangat tertarik dan akan menjadi pendatang baru untuk ikut serta mempelajari logika fuzzy. Logika fuzzy dikatakan sebagai logika baru yang lama, sebab ilmu tentang logika fuzzy modern dan metode baru ditemukan beberapa tahun yang lalu, padahal sebenarnya konsep tentang logika fuzzy itu sendiri sudah ada pada diri kita sejak lama. 
Untuk mendapatkan output pada logika fuzzy, diperlukan 4 tahapan:

a. Pembentukan himpunan fuzzy. Pada proses fuzzifikasi langkah yang pertama adalah menentukan Variabel fuzzy dan himpunan fuzzy-nya. Kemudian tentukan derajat keanggotaan antara data masukan fuzzy dengan himpunan fuzzy yang telah didefenisikan untuk setiap variabel masukan sistem dari setiap aturan fuzzy. Variabel input maupun variabel output dibagi menjadi satu atau lebih himpunan fuzzy.

b. Aplikasi fungsi implikasi. Hasil implikasi fuzzy dari setiap aturan ini kemudian digabungkan untuk menghasilkan keluaran inferensi fuzzy.

c. Komposisi Aturan (rule). Tidak seperti penalaran monoton, apabila sistem terdiri dari beberapa aturan, maka inferensi diperoleh dari kumpulan dan korelasi antar aturan. Ada 3 metode yang digunakan dalam melakukan inferensi sistem fuzzy, yaitu: max, additive dan probabilistik $\mathrm{OR}$.

d. Penegasan (defuzzy). Input dari proses defuzzifikasi adalah suatu himpunan fuzzy yang diperoleh dari komposisi aturan-aturan fuzzy, sedangkan output yang dihasilkan merupakan suatu bilangan pada domain himpunan fuzzy tersebut (Marimin, 2010).

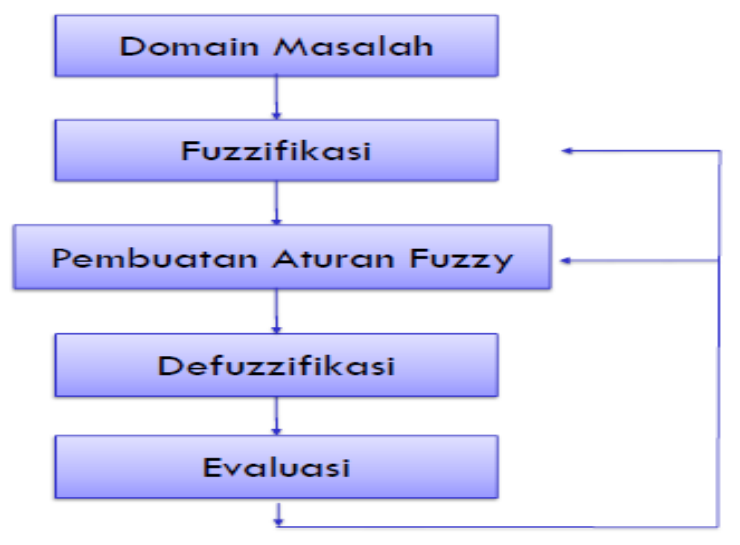

Gambar 1. Tahapan Fuzzy

5. Matlab Toolbox: Fuzzy

Agar dapat menggunakan fungsi-fungsi logika fuzzy yang ada pada Matlab, maka harus diinstallkan terlebih dahulu ToolboxFuzzy.Fuzzy Logictoolbox (FLT) memberikan fasilitas Graphical User Interface (GUI) untuk mempermudah dalam membangun, mengedit, dan mengobservasi sistem penalaran fuzzy, yaitu (Kusumadewi, 2002):

1) Fuzzy Inference System (FIS) Editor; 2) Membership Function Editor; 3) Rule Editor; 4) Rule Viewer; 5) Surface Viewer.

Motivasi utama teori fuzzy logic adalah memetakan sebuah ruang input ke dalam ruang output dengan menggunakan IF - THEN rules. Pemetaan dilakukan dalam suatu FIS, urutan rule bisa sembarang.FIS mengevaluasi semua rule secara simultan untuk menghasilkan kesimpulan. Oleh karenanya, semua rule harus didefinisikan lebih dahulu sebelum kita membangun sebuah FIS yang akan digunakan untuk menginterpretasikan semua rule tersebut.

Mekanisme dalam FIS bisa dirangkum yaitu: FIS adalah sebuah metode yang menginterpretasikan harga-harga dalam vektor input, menarik kesimpulan berdasarkan sekumpulan IF-THEN rule yang diberikan, dan kemudian menghasilkan vektor output (Naba, 2009).

\section{Metodologi Penelitian}

Penelitian yang dilaksanakan adalah analisis kuantitatif. Untuk mendapatkan gambaran yang lengkap tentang objek yang akan diteliti dengan melakukan pengamatan langsung di lapangan. Model evaluasi kinerja karyawan dengan metode fuzzy sugeno, berdasarkan hasil 
kuesioner dan wawancara dengan Manajer cabang Kemudian dilakukan pengujian tingkat akurasi dari model yang dihasilkan.

Alur penelitian model evaluasi kinerja karyawan menggunakan logika fuzzy melalui beberapa tahap dalam pengembangannya, yaitu:

1. Penelitian pendahuluan

Kegiatan yang dilakukan pada saat studi pendahuluan yaitu: mengumpulkan materimateri kepustakaan yang berhubungan dengan judul penelitian. Kemudian langkah selanjutnya yaitu:pengambilan data primer di resto ABTL. Dari data tersebut akan di dapat beberapa kriteria yang digunakan untuk penelitian lebih lanjut.

2. Data Kuesioner

Sampel data yang digunakan pada penelitian ini adalah data kuesioner dari karyawan resto ABTL pada cabang Kalisari yang diisi oleh Manajer cabang dan data wawancara dengan Manajer cabang.

3. Pengolah data

Data yang diperoleh akan diolah menggunakan pendekatan Logika Fuzzy dengan bantuan toolbox Matlab.

Berikut adalah variabel yang akan digunakan dan dianalisa.

a. Melakukan dekomposisi variabel model menjadi himpunan fuzzy. Variabel yang digunakan yaitu:

Tabel 1. Semesta Pembicaraan Variabel Fuzzy

\begin{tabular}{lll}
\hline Fungsi & Nama Variabel & Semesta Pembicaraan \\
\hline \multirow{4}{*}{ Input } & Kehadiran & {$[0-100]$} \\
& Pelayanan & {$[0-100]$} \\
& Penampilan & {$[0-100]$} \\
& Kerjasama & {$[0-100]$} \\
& Tanggungjawab & {$[0-100]$} \\
Output & Skor Hasil kuesioner & {$[0-100]$} \\
\hline
\end{tabular}

b. Membentuk himpunan fuzzy.

Tabel 2. Himpunan Fuzzy

\begin{tabular}{|c|c|c|}
\hline Nama Variabel & Nama Himpunan Fuzzy & Domain \\
\hline \multirow{3}{*}{ Kehadiran } & Buruk & {$[0-50]$} \\
\hline & Cukup & {$[40-80]$} \\
\hline & Baik & {$[70-100]$} \\
\hline \multirow{3}{*}{ Pelayanan } & Buruk & {$[0-50]$} \\
\hline & Cukup & {$[40-80]$} \\
\hline & Baik & {$[70-100]$} \\
\hline \multirow{3}{*}{ Penampilan } & Buruk & {$[0-50]$} \\
\hline & Cukup & {$[40-80]$} \\
\hline & Baik & {$[70-100]$} \\
\hline \multirow[t]{3}{*}{ Kerjasama } & Buruk & {$[0-50]$} \\
\hline & Cukup & {$[40-80]$} \\
\hline & Baik & {$[70-100]$} \\
\hline \multirow{3}{*}{ Tanggungjawab } & Buruk & {$[0-50]$} \\
\hline & Cukup & {$[40-80]$} \\
\hline & Baik & {$[70-100]$} \\
\hline
\end{tabular}

4. Metode Pengumpulan Data.

Penelitian yang dilakukan untuk menghasilkan data dan informasi yang diperlukan serta berhubungan dengan hal yang akan ditulis. Untuk mengumpulkan data serta informasi yang diperlukan oleh peneliti menggunakan metode wawancara dan kuesioner dari 
Manajer.Sampel pada penelitian ini adalah karyawan resto ABTL cabang Kalisari yang berjumlah 15 karyawan.

5. Teknik Analisis Data.

Analisis data menggunakan kuantitatif dengan kaidah-kaidah matematika terhadap data angka atau numerik. Pembentukan himpunan fuzzy pada variabel input maupun variabel output dibagi menjadi satu atau lebih himpunan fuzzy. Aplikasi fungsi implikasi yang digunakan untuk tiap-tiap aturan adalah fungsi min. Penegasan (defuzzy) menggunakan bantuan software matlab dengan menggunakan fasilitas yang disediakan pada toolboxfuzzy.

6. Pengujian Aplikasi.

Pengujian aplikasi ini dilakukan untuk memastikan perangkat lunak yang telah dibuat sesuai dengan kebutuhan.Pengujian validasi untuk menguji apakah spesifikasi kebutuhan sudah sesuai dengan yang diharapkan.

\section{Hasil dan Pembahasan}

1. Analisis Data.

Data yang digunakan dalam penelitian ini didapatkan dari resto ABTL cabang Kalisari, yaitu: data kriteria penilaian dan data 15 karyawan yang dinilai. Aspek evaluasi kinerja karyawan dijabarkan dalam 5 kriteria penilaian, yaitu: kehadiran, pelayanan, penampilan, kerjasama dan tanggung-jawab.

Kriteria-kriteria penilaian tersebut dibentuk dalam himpunan fuzzy sebagai berikut :

Sementara itu, pembicaraan masing-masing variabel adalah [0 - 100]. Variabel ini dibagi dalam tiga himpunan fuzzy, yaitu: "Buruk", "Cukup", dan "Baik". Himpunan fuzzy "Buruk" memiliki domain [0-50], himpunan fuzzy "Cukup" memiliki domain [4080], dan himpunan fuzzy "Baik" memiliki domain [70-100].

Variabel-variabel penilaian dipresentasikan dalam kurva linear dan segitiga sebagai berikut :

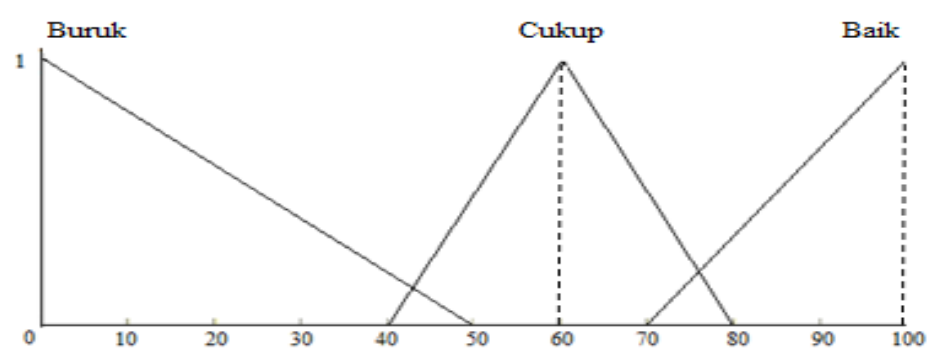

Gambar 2. Himpunan Fuzzy Kriteria Penilaian.

Persamaan :

$$
\begin{aligned}
& \mu \text { Buruk }[x]=\left\{\begin{array}{cc}
(50-x) /(50-0) & ; 0 \leq x \leq 50 \\
0 & ; x \geq 50
\end{array}\right. \\
& \mu \text { Cukup }[x]=\left\{\begin{array}{cc}
0 & ; x \leq 40 \text { atau } x \geq 80 \\
(x-40) /(60-40) & ; 60 \leq x \leq 60 \\
(80-x) /(80-60) & ; x \leq 70
\end{array}\right. \\
& \mu \text { Baik }[x]=\left\{\begin{array}{cc}
0 & ; 70 \leq x \leq 100 \\
(x-70) /(100-70) & ; x \geq 100 \\
1 &
\end{array}\right.
\end{aligned}
$$


2. Rancangan Model

a. Rancangan Fuzzy

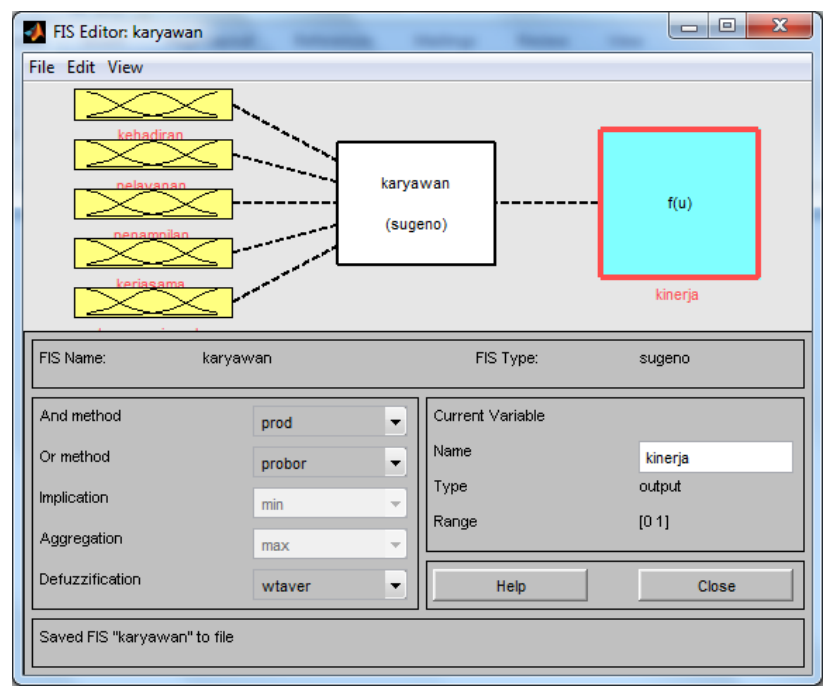

Gambar 3. FIS Editor Penilaian Kinerja Karyawan

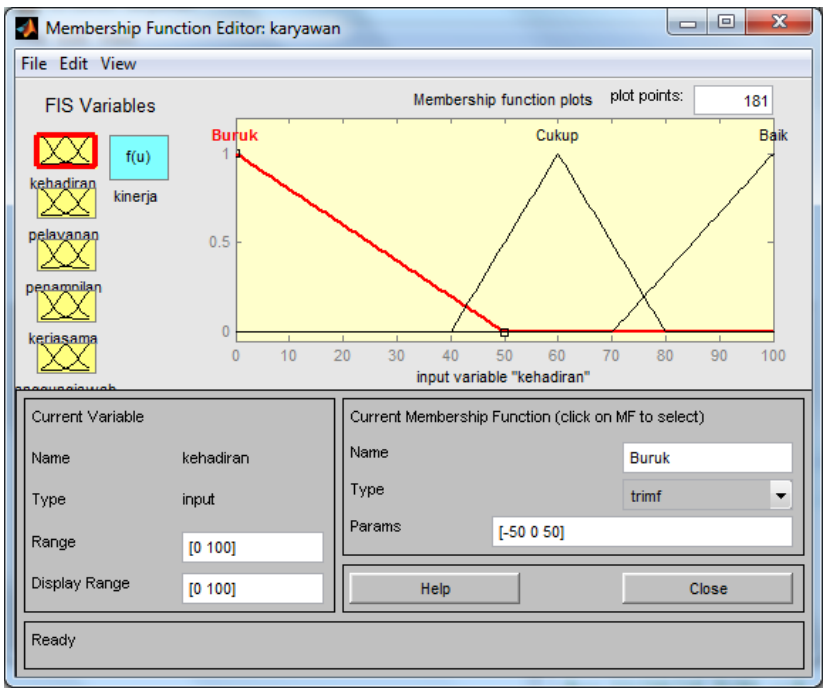

Gambar 4. Membership Function Editor Kriteria Penilaian. 


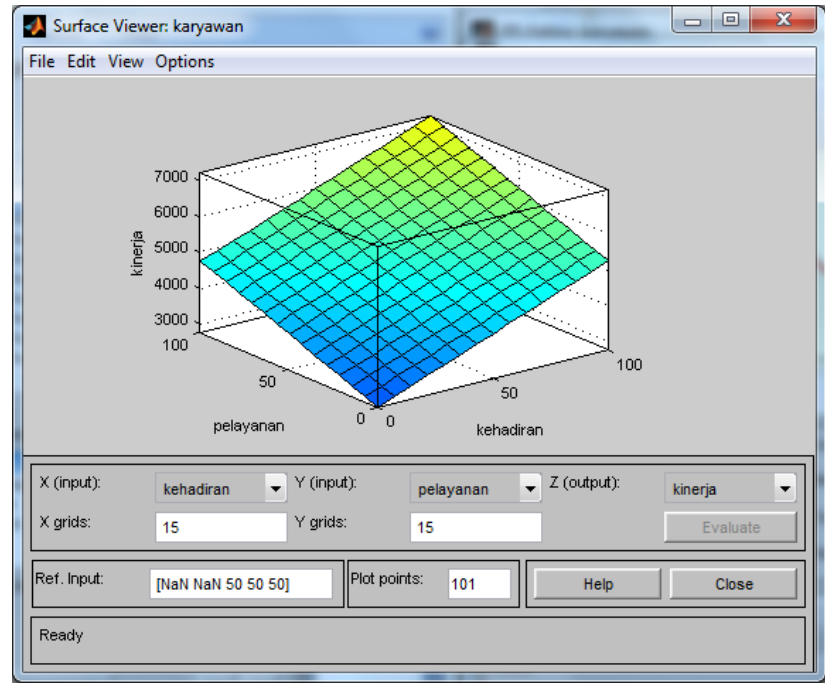

Gambar 5. Surface Viewer Penilaian Kinerja.

b. Pembentukan Aturan Fuzzy.

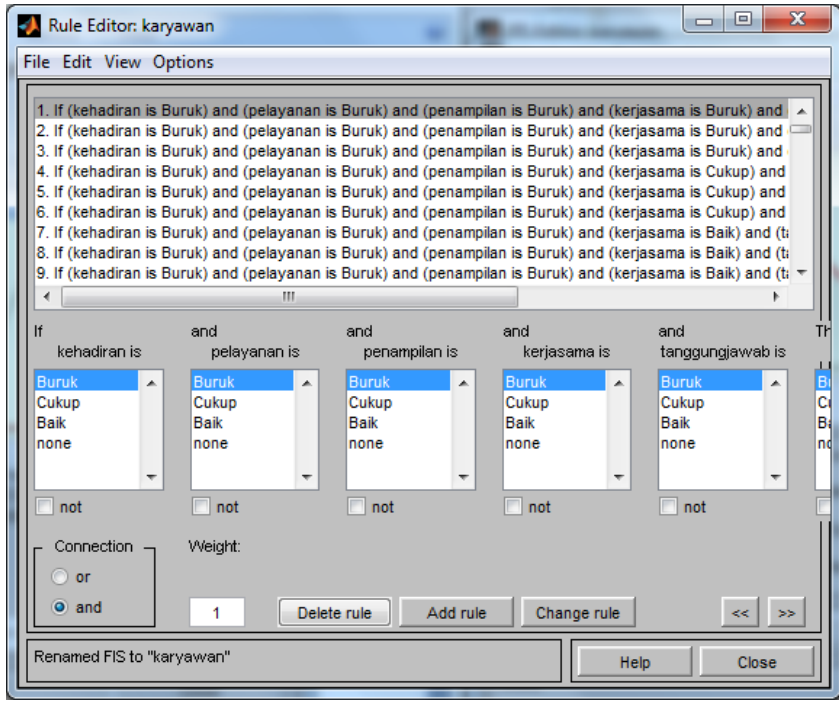

Gambar 6. Rule Editor Penilaian Kinerja.

3. Graphical User Interface (GUI) Penilaian Kinerja Karyawan

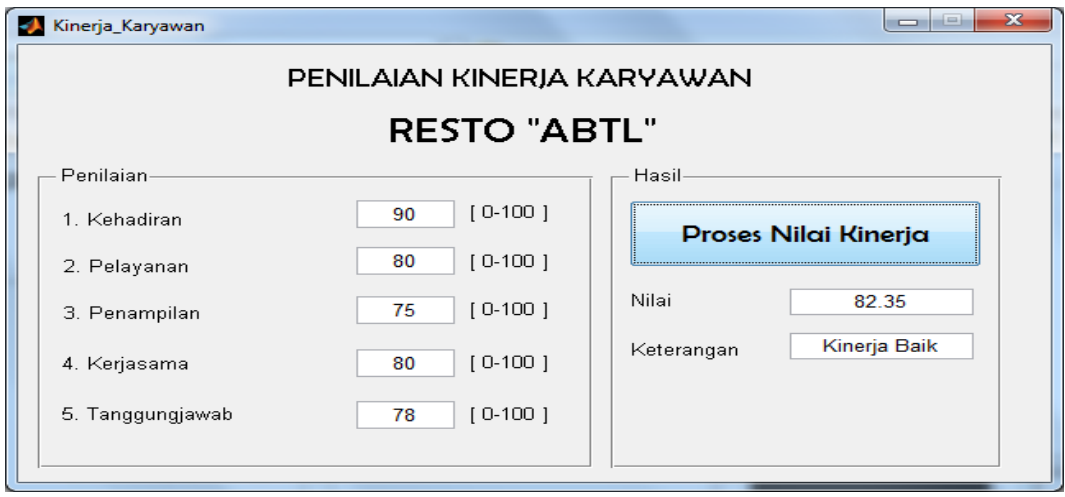

Gambar 7. Model Penilaian Knerja Karyawan 
Model evaluasi kinerja karyawan dibuat menggunakantools Matlab v7.9.0 (R2009b) dengan logika Fuzzy Sugeno. Setelah proses penginputan data selesai, maka selanjutnya akan dilakukan proses evaluasi kinerja karyawan yang akan menghasilkan output berupa nilai karyawan dan hasil kinerja karyawan.

\section{Simpulan dan Saran}

\section{Simpulan}

Berdasarkan pembahasan hasil penelitian yang telah dibahas pada bab sebelumnya, maka dapat diambil kesimpulan sebagai berikut:

a. Evaluasi kinerja karyawan dapat dibangun dengan pendekatan logika fuzzy.

b. Evaluasi kinerja karyawan dengan sistem pendukung keputusan menggunakan pendekatan logika fuzzy lebih objektif dari pada penilaian secara manual.

c. Evaluasi kinerja karyawan dengan sistem pendukung keputusan menggunakan pendekatan logika fuzzy lebih efektif dan efisien.

d. Evaluasi kinerja karyawan dengan pendekatan logika fuzzy menggunakan 5 kriteria dalam menentukan keputusan.

\section{Saran}

Berdasarkan hasil penelitian dan kesimpulan, selanjutnya peneliti dapat memberikan beberapa saran yang relevan dengan hasil penelitian.Saran ini berupa masukan-masukan yang ditujukan untuk penelitian selanjutnya.

a. Kriteria-kriteria dalam evaluasi kinerja karyawan dapat dikembangkan untuk penyempurnaan aplikasi.

b. Perlu dikembangkan penelitian lanjutan yaitu: evaluasi kinerja karyawan menggunakan metode lain atau dikomparasikan untuk mendapatkan aplikasi dengan nilai akurasi yang paling tinggi.

\section{Daftar Pustaka}

Ganevi, Riesda.,\& Purnama, B. E. (2014). Sistem Pendukung Keputusan Penilaian Kinerja Guru Sekolah Menengah Pertama Negeri (SMP N) 1 Pacitan.

Haryanto, T. (2012). Logika Fuzzy dan Sistem Pakar Berbasis Fuzzy, Materi Kuliah, Departemen Ilmu Komputer. Bogor: Institut Pertanian Bogor.

Kusumadewi, S. (2002). Analisis Desain Sistem Fuzzy menggunakan Tool Box Matlab ( Edisi ke-1). Yogyakarta: Graha Ilmu.

Kusumadewi, S., \& Purnomo, H. (2010). Aplikasi Logika Fuzzy Untuk Pendukung Keputusan (Edisi ke-2). Yogyakarta: Graha Ilmu.

Maman. (2006). Sistem Pendukung Keputusan: Model Penentuan Siswa Teladan pada SMK YP Karya 1Tangerang dengan pendekatan logika fuzzy.

Marimin. (2012). Penalaran Fuzzy. Materi Kuliah, Departemen Ilmu Komputer. Bogor: Institut Pertanian Bogor.

Marimin. (2005). Teori dan aplikasi sistem pakar dalam tehnologi manajerial. Bogor: IPBPress.

Marimin., \& Maghfiroh N. (2010). Aplikasi Pengambilan Keputusan dalam Manajemen Rantai Pasok. Cetakan ke-1. Bogor: IPB-Press.

Naba, A. (2009).Belajar Cepat Fuzzy Logic menggunakan Matlab. Yogyakarta: Andi Offset. 